\title{
The effect of irradiance on the carbon balance and tissue characteristics of five herbaceous species differing in shade-tolerance
}

\author{
Thijs L. Pons ${ }^{1 *}$ and Hendrik Poorter ${ }^{2}$ \\ 1 Plant Ecophysiology, Institute of Environmental Sciences, Utrecht University, Utrecht, Netherlands \\ 2 IBG-2 Plant Sciences, Forschungszentrum Jülich GmbH, Jülich, Germany
}

\section{Edited by:}

Bertrand Muller, Institut National de la Recherche Agronomique, France

\section{Reviewed by:}

Dirk Vanderklein, Montclair State

University, USA

Cristina Nabais, University of

Coimbra, Portugal

\section{${ }^{*}$ Correspondence:}

Thijs L. Pons, Plant Ecophysiology, Institute of Environmental Sciences, Utrecht University, Padualaan 8, $3508 \mathrm{CH}$ Utrecht, Netherlands e-mail: t.l.pons@uu.nl
The carbon balance is defined here as the partitioning of daily whole-plant gross $\mathrm{CO}_{2}$ assimilation $(A)$ in $C$ available for growth and $C$ required for respiration $(R)$. A scales positively with growth irradiance and there is evidence for an irradiance dependence of $R$ as well. Here we ask if $R$ as a fraction of $A$ is also irradiance dependent, whether there are systematic differences in $\mathrm{C}$-balance between shade-tolerant and shade-intolerant species, and what the causes could be. Growth, gas exchange, chemical composition and leaf structure were analyzed for two shade-tolerant and three shade-intolerant herbaceous species that were hydroponically grown in a growth room at five irradiances from $20 \mu \mathrm{mol}$ $\mathrm{m}^{-2} \mathrm{~s}^{-1}\left(1.2 \mathrm{~mol} \mathrm{~m}^{-2}\right.$ day $\left.^{-1}\right)$ to $500 \mu \mathrm{mol} \mathrm{m}{ }^{-2} \mathrm{~s}^{-1}\left(30 \mathrm{~mol} \mathrm{~m}^{-2}\right.$ day $\left.{ }^{-1}\right)$. Growth analysis showed little difference between species in unit leaf rate (dry mass increase per unit leaf area) at low irradiance, but lower rates for the shade-tolerant species at high irradiance, mainly as a result of their lower light-saturated rate of photosynthesis. This resulted in lower relative growth rates in these conditions. Daily whole-plant $R$ scaled with $A$ in a very tight manner, giving a remarkably constant $R / A$ ratio of around 0.3 for all but the lowest irradiance. Although some shade-intolerant species showed tendencies toward a higher $R / A$ and inefficiencies in terms of carbon and nitrogen investment in their leaves, no conclusive evidence was found for systematic differences in C-balance between the shade-tolerant and intolerant species at the lowest irradiance. Leaf tissue of the shade-tolerant species was characterized by high dry matter percentages, C-concentration and construction costs, which could be associated with a better defense in shade environments where leaf longevity matters. We conclude that shade-intolerant species have a competitive advantage at high irradiance due to superior potential growth rates, but that shade-tolerance is not necessarily associated with a better C-balance at low irradiance. Under those conditions tolerance to other stresses is probably more important for the performance of shade-tolerant species.

Keywords: construction costs, growth analysis, photosynthesis, root respiration, scaling slope analysis, shoot respiration, whole-plant gas exchange

\section{INTRODUCTION}

The rate of photosynthesis typically increases with irradiance, particularly in the lower light range. Plant growth, defined here as the increase in dry mass, can then be expected to increase as well, and this is indeed generally observed (Poorter and van der Werf, 1998). At very low irradiances, as found under a dense leaf canopy, photosynthetic rates are inevitably very low. This does not imply, however, that maximization of gross C-gain and minimization of C-loss is necessarily the best strategy for survival under these conditions. Low light not only strongly limits $\mathrm{C}$-availability for growth but may also critically restrict the energy supply for essential metabolic processes, such as maintenance of cellular gradients or protein turnover. Under these conditions, a proper balance between allocation of $\mathrm{C}$ to growth and to respiration may be important for survival, as reserves for storage on the one hand and the generation of metabolic energy on the other may be required to meet the challenges of the stressful shade environment.
The rate of photosynthesis per unit leaf area at the growth irradiance $\left(A_{\text {growth }}\right)$ is not the only plant trait that determines the biomass increase per unit biomass present (relative growth rate; RGR). From a C-balance perspective, at least four other plant traits co-determine RGR. These are the leaf area per unit leaf mass (specific leaf area, SLA), the fraction of total plant mass present in leaves (leaf mass fraction, LMF), the fraction of daily gross $\mathrm{C}$-gain that is spent in whole-plant respiration $(R / A)$ and the C-concentration of the biomass $([C])$. In formula:

$$
\mathrm{RGR}=\left\{A_{\text {growth }} \cdot(1-R / A) \cdot \mathrm{SLA} \cdot \mathrm{LMF}\right\} /[C]
$$

Further explanation of the growth equations is given in Appendix 1 and of abbreviations and symbols in Table 1. Each of the variables in equation 1 can be irradiance-dependent. The SLA decreases strongly with increasing irradiance in most plants, which is the result of both an increasing leaf thickness and leaf 
tissue density (Poorter et al., 2009). This is associated with a higher photosynthetic capacity per unit leaf area. The LMF generally does not change much with irradiance (Poorter et al., 2012b). Variation in $[C]$ with growth irradiance is also small, as was shown for leaves at different positions in tree crowns and for whole plants in a shading experiment (Niinemets, 1999; Poorter et al., 2006; Petritan et al., 2010). Additional components, such as losses through tissue death, exudation and volatilization, are quantitatively of little importance in most juvenile plants and are ignored in this study.

The fourth component in equation 1 is the R/A ratio. Wholeplant $R$ can conceptually be divided into $R$ associated with growth-and thus processes such as ion uptake and synthesis of new compounds of biomass - and $R$ associated with maintenance, which includes turnover of cellular compounds and maintenance of solute gradients (Amthor, 2000). Growth $R$ is thus likely to diminish at low irradiance because of a reduced growth rate. However, the same does not necessarily apply to maintenance $R$. If we assume maintenance $R$ to be constant, because the associated cellular processes are not affected by light, it would follow that total $R$ diminishes less with decreasing growth irradiance as compared to $A$, with a higher $R / A$ ratio at low irradiance as a consequence. In juvenile herbaceous plants growing in optimal conditions $R$ integrated over $24 \mathrm{~h}$ is circa one third of daily $A$ (Poorter, 2002). The few data available on the growth irradiance effect on $R / A$ show rather constant values, notwithstanding that $A$ increases strongly with irradiance (McCree and Troughton, 1966; Poorter, 2002). However, the data are very limited and this hampers a more generalized picture.

Shade-tolerant species are adapted to conditions where net Cgain is typically low. It could therefore be expected that, compared with shade-intolerant species, their C-balance is more favorable at low irradiance. Comparisons of the C-balance between shadetolerant and intolerant species have been made at the leaf level (e.g., Noguchi et al., 1996, 2005; Lusk, 2002; Craine and Reich, 2005). These studies indicate that there are no differences in gross photosynthesis in these conditions. There is, however, some evidence for a lower leaf $R$ and thus lower light compensation points for leaves of shade-tolerant species, but differences are small and not always consistent (Walters and Reich, 1999). However, rather than the leaf-level it is the C-balance at the whole-plant level that counts (Givnish, 1988). Differences between shade-tolerant and intolerant species at the level of whole-plant gas exchange at low irradiance have not been systematically investigated. The question thus remains whether shade-tolerant species have a superior C-balance in shade.

Our study aims for a better understanding of how the Cbalance of plants depends on irradiance. An experiment was carried out where plants were grown at different daily irradiances representative of the full range from dense canopy shade to full daylight. First, we establish the basis for further analysis by determining the RGR and its underlying variables through classical growth analysis. Second, we address the question to what extent the components of the C-balance change with the growth irradiance. The evidence presented above suggests a rather constant daily whole-plant $R$ as a fraction of photosynthetic C-gain $(R / A)$. However, we hypothesize that the $R / A$ should increase when $A$ decreases to very low values at low irradiance. A third question

Table 1 | Abbreviations and symbols, definitions of the variables and units used in this paper.

Abbreviations Explanation Units
and symbols

A
$A_{a}$

Agrowth

$A_{\text {sat }}$

$A_{\mathrm{m}}$

[C]

CC

CUE

GRC

LAR

LMA

LMF

$N_{a}$

$N_{\mathrm{m}}$

$\mathrm{NAR}_{\text {ge }}$

PPFD

PNUE

$R$

$R_{\mathrm{m}}$

$R_{\mathrm{a}}$

R/A

RGR

RMF

SLA

SMF

ULR
Rate of $\mathrm{CO}_{2}$ assimilation or photosynthesis

$A$ per unit leaf area

$A$ at the growth irradiance, generally per unit leaf area

A per unit leaf area at light saturation at the leaf level

A per unit dry mass

Carbon concentration; C per unit dry

mass

Construction costs; glucose required

to synthesize a unit of dry matter

Carbon use efficiency; the fraction of assimilated carbon invested in growth (CUE $=1-R / A)$

Growth response coefficient

Leaf area ratio; leaf area per unit plant $\mathrm{m}^{2} \mathrm{~kg}^{-1}$ dry mass

Leaf dry mass per unit leaf area $\quad \mathrm{g} \mathrm{m}^{-2}$

$(\mathrm{LMA}=1 / \mathrm{SLA})$

Leaf mass fraction; leaf dry mass per $\mathrm{g} \mathrm{g}^{-1}$

unit plant dry mass

Leaf nitrogen per unit leaf area $\quad \mathrm{mmol} \mathrm{m}^{-2}$

Nitrogen per unit dry mass in plant $\quad \mathrm{mg} \mathrm{g}^{-1}$

tissue

Daily net assimilation rate calculated $\mathrm{g} \mathrm{m}^{-2}$ day $^{-1}$

from gas exchange

Photon flux density, restricted to

photosynthetically active radiation

Photosynthetic nitrogen use

efficiency; $A$ per unit $\mathrm{N}$

Rate of respiration, measured as $\mathrm{CO}_{2}$ release or $\mathrm{O}_{2}$ consumption

$R$ per unit dry mass

$R$ per unit leaf area

$\mathrm{nmol} \mathrm{g} \mathrm{s}^{-1} \mathrm{~s}^{-1}$

$R$ as a fraction of gross $A$, mostly for $\mathrm{mol} \mathrm{mol}^{-1}$

whole plants at a daily ( $24 \mathrm{~h}$ ) basis

Relative growth rate; dry mass $\mathrm{mg} \mathrm{g}^{-1}$ day $^{-1}$

increment per unit dry mass and time

Root mass fraction; root dry mass per $\mathrm{g} \mathrm{g}^{-1}$

unit plant dry mass

Specific leaf area; leaf area per unit $\quad \mathrm{m}^{2} \mathrm{~kg}^{-1}$

leaf dry mass (SLA $=1 /$ LMA)

Stem mass fraction; stem plus petiole $\mathrm{g} \mathrm{g}^{-1}$

dry mass per unit plant dry mass

Unit leaf rate; dry mass increment per $\mathrm{g} \mathrm{m}^{-2} \mathrm{day}^{-1}$

unit leaf area and time

we analyze is whether there are species-specific differences in the irradiance dependence of the C-balance and its components between shade-tolerant and intolerant species, because we hypothesize that shade-tolerant species may maintain a more favorable C-balance at low irradiance. Although the number of species included is not sufficient for broad generalizations, the 
comparison of the five species should give indications of such differences. We furthermore address the question what the causes of the possible dependence of the C-balance on irradiance and shade-tolerance could be. For that purpose we measured leaflevel photosynthesis, leaf structure and aspects of the chemical composition.

\section{MATERIALS AND METHODS PLANT MATERIAL AND EXPERIMENTAL DESIGN}

The experiments were carried out with juvenile plants of five herbaceous eudicotyledonous species, two shade-tolerant (Geum urbanum L. and Impatiens parviflora DC.), and three shadeintolerant species (Chenopodium album L., Helianthus annuus L. and Rumex palustris Sm.) Seeds were collected in their natural habitat in the vicinity of Utrecht, except for Rumex, which was collected in a floodplain of the river Waal near Nijmegen and Helianthus, which was obtained commercially. Impatiens seeds were stratified at $4^{\circ} \mathrm{C}$ for 2 months. Seeds were germinated on sand in the growth room at an irradiance of $200 \mu \mathrm{mol} \mathrm{m}^{-2} \mathrm{~s}^{-1}$. When the first true leaves were formed, the plants were transferred to $33 \mathrm{~L}$ containers with an aerated nutrient solution, having a concentration of $2 \mathrm{mM} \mathrm{NO}_{3}{ }^{-}$and other nutrients in proportion as in Hoagland and Snijder (1933). The $\mathrm{pH}$ was adjusted regularly at 5.6 and the solution was changed weekly. Conditions in the growth room were a constant air temperature of $20^{\circ} \mathrm{C}$, a relative air humidity $70 \%$ and a photoperiod of $16 \mathrm{~h}$. Five levels of irradiance (provided by Philips HPI $400 \mathrm{~W}$ lamps) were achieved by creating compartments with reflective walls and neutral shade screen on top. The lower part of each compartment was largely open for ventilation. Irradiance levels were $\sim 20,50,100,220$, and $500 \mu \mathrm{mol} \mathrm{m}^{-2} \mathrm{~s}^{-1}$ photosynthetically active radiation, equivalent to daily irradiances of $1.2,2.9,5.8,12.7$, and $28.8 \mathrm{~mol} \mathrm{~m}^{-2} \mathrm{day}^{-1}$, respectively. Irradiance was checked regularly during growth of the plants.

\section{DESTRUCTIVE HARVESTING}

To minimize the effect of plant-to-plant variation on the growth parameter estimates, plants of each treatment and species were divided by eye in two size groups before each harvest (Poorter, 1989). Two plants from each size class were then randomly sampled at each of three harvest occasions. The experiment was repeated once and the data were combined, thus resulting in eight plants per harvest, light condition and species, 600 plants in total. Each of the sampled plants was divided into leaf blades, stems plus petioles and roots, after which leaf area and organ fresh mass were determined. Dry mass was measured after drying at $70^{\circ} \mathrm{C}$ for $48 \mathrm{~h}$. The first harvest was at a whole-plant fresh mass of about $1.5 \mathrm{~g}$, but tended to be somewhat lower at low irradiance due to low initial growth rates and somewhat higher for the large-seeded Helianthus. In order to further minimize size differences over the harvest intervals, time until the third harvest varied between 7 and 20 days, depending on growth rate.

\section{GAS EXCHANGE MEASUREMENTS}

Right before the second harvest, plants were measured for their rate of net photosynthesis and the respiration of shoots and roots. The plants were taken from the growth room, their above-ground parts were enclosed in gas exchange cuvettes and measured for
$\mathrm{CO}_{2}$ uptake at the growth irradiance after reaching steady state ( $\left.A_{\text {growth }}\right)$. After $2 \mathrm{~h}$ in the dark, the $\mathrm{CO}_{2}$ release of the shoots was measured ( shoot $R$ ). Thereafter, the roots were detached, enclosed in light-tight cuvettes with an oxygen electrode for the measurement of $\mathrm{O}_{2}$ consumption in water (root $R$ ). Details of the technique are given by Poorter et al. (1990). A short description is given below.

In the $\mathrm{CO}_{2}$ exchange setup where $A_{\text {growth }}$ and shoot $R$ were measured, light was provided by similar lamps as in the growth chamber. Measurement irradiance and temperature were made identical to the growth conditions. $\mathrm{CO}_{2}$ concentration in the incoming air was maintained at $400 \mu \mathrm{mol} \mathrm{mol}^{-1}$, and water vapor partial pressure was set at $1200 \mathrm{~Pa}$. $\mathrm{CO}_{2}$ uptake and transpiration modified plant cuvette values to a $\mathrm{CO}_{2}$ concentration of $\sim 380 \mu \mathrm{mol} \mathrm{mol}^{-1}$ and a relative humidity of circa $65 \%$. The difference in $\mathrm{CO}_{2}$ and $\mathrm{H}_{2} \mathrm{O}$ concentration between inlet and outlet air was measured with an IRGA (Licor-6262, Lincoln, NE, USA).

For the measurement of root respiration, fresh nutrient solution was equilibrated with air at the measurement temperature of $20^{\circ} \mathrm{C}$. The full root system was detached from the shoots and enclosed in a custom-made air-tight cuvette completely filled with nutrient solution. The rate of decrease of the $\mathrm{O}_{2}$ concentration was measured over a period of $15 \mathrm{~min}$ with a Clark electrode (Yellow Group Instruments, OH, USA). Due to the small root systems of the plants from the lowest irradiances, the resolution was insufficient for precise measurements. In those cases roots of two individuals were combined for better sensitivity. Unforeseen technical problems with the system caused that only for two species reliable root respiration measurements are available for the full range of growth irradiances.

For separate plants from each species and irradiance treatment, leaf-level gas exchange was measured on recently matured leaves $(n=3)$. Leaves were enclosed in leaf chambers and measurements were done at growth irradiance and at light-saturation. The setup for these leaf-level measurements has been described by Pons and Welschen (2002).

\section{CHEMICAL ANALYSIS}

Chemical composition of dry matter was measured on two independent bulk samples per light level and species, for leaf blade material and the rest of the plants separately. $\mathrm{C}$ and $\mathrm{N}$ concentrations were measured with an elemental analyzer (Carlo Erba, Milan, Italy). Nitrate was determined colorimetrically after extraction with boiling water, and mineral content determined in ash in combination with ash alkalinity. A full description of procedures and calculations is given at Prometheus wiki (http:// prometheuswiki.publish.csiro.au).

\section{CALCULATIONS}

Growth parameters were calculated as follows. For each of the plants harvested we kept track of whether they were a-priori classified into the "small or large" group. From each category within each experiment we randomly linked one plant of a given harvest to a randomly chosen plant of the other two harvests, giving eight time-series represented by triplets of plants. For each of these time series a linear regression of $\log _{\mathrm{e}}$-transformed dry masses over time was calculated, with the slope being the RGR. Morphological (SLA, LAR), allocation (LMF, SMF, RMF) 
and tissue density variables were calculated as average values per triplet. Finally, for each triplet ULR was calculated from RGR/LAR. Each of the eight growth parameter values was thus based on information from an independent set of plants.

The growth response coefficients (GRCs) of components of the RGR summarize the contribution of the variation in the respective growth parameters of equation 1 to the variation in RGR. To this end, a scaling slope analysis was carried out by calculating the regression coefficients of log-transformed growth parameter data versus log-transformed RGR (Poorter and van der Werf, 1998; Renton and Poorter, 2011). The same analysis was done for the ULR and its components, and the contribution of leaf density and leaf thickness to the increase of LMA with irradiance.

$A_{\text {growth }}$ was calculated from the $\mathrm{CO}_{2}$ uptake in the light, and shoot $R$ from the $\mathrm{CO}_{2}$ release in the dark. Values were expressed per unit leaf area and dry mass as appropriate. Root $R$ was calculated from root $\mathrm{O}_{2}$ consumption. For the calculation of whole-plant $R$ in $\mathrm{CO}_{2}$ units, we assumed a respiratory quotient of 1.2, as is often the case in nitrate-fed plants (Poorter et al., 1990). Whole-plant $R / A$, integrated over $24 \mathrm{~h}$, was calculated on the basis of gross photosynthesis by adding shoot $R$ to measured shoot net $A$, assuming identical $R$ in light and dark. Hence, the $R$ in $R / A$ refers to $24 \mathrm{~h}$ of whole-plant $R$ and the $A$ to $16 \mathrm{~h}$ shoot gross photosynthesis, both calculated on the same expression basis.

A Two-Way ANOVA was performed on $\log _{\mathrm{e}}$-transformed data using the aov procedure in R (R Core Team, 2013), with Species and Irradiance as main factors. Specific a-priori contrasts between the shade-tolerant and shade-intolerant species were made for the main effect Species, as well as for the Species $\times$ Irradiance interaction.

\section{RESULTS}

\section{GROWTH ANALYSIS}

Light had a strong and statistically highly significant effect on most of the growth variables (Figure 1, Table 2). All species had a positive RGR even at the lowest irradiance (Figure 1A), and therefore a positive C-balance. The increase in RGR with irradiance was strong in the lower light range and much less in the higher range. Interestingly, as far as there were differences in RGR between species at the low-irradiance range, there was no clear association with shade-tolerance. However, above an irradiance of $\sim 100 \mu \mathrm{mol} \mathrm{m} \mathrm{m}^{-2} \mathrm{~s}^{-1}$ the two shade-tolerant species increased RGR substantially less compared to the intolerant ones (Figure 1A, Table 2). This resulted at the highest irradiance in RGR's of on average 244 and $354 \mathrm{mg} \mathrm{g}^{-1}$ day ${ }^{-1}$ for the shadetolerant and intolerant species, respectively. The ULR across the low irradiance range $\left(20-100 \mu \mathrm{mol} \mathrm{m} \mathrm{m}^{-2} \mathrm{~s}^{-1}\right)$ was very similar for all species (Figure 1B). For the shade-intolerant species, ULR increased in an almost linear fashion with irradiance. For the shade-tolerant ones, the ULR increase was less strong, explaining to a large extent their lower RGR under these conditions.

All plants showed a decrease of SLA with irradiance, strongly in the lower and less so in the higher range (Figure 1C). Two of the shade-intolerant species, Helianthus and Chenopodium, deviated in the lower light range from the general trend because they did not develop a high SLA there (Figure 1C). The decrease of SLA with irradiance counteracted the almost linear increase of the ULR (Figure 1B), resulting in a curvilinearly increasing RGR. In contrast, the LMF, which is the other morphological component that determines RGR (equation 1, Appendix 1), remained relatively constant (Figure 1D). The exception was Rumex, which showed a decreasing trend of LMF with irradiance. All species showed a moderate increase in RMF (Figure 1D) and a decrease in SMF (Supplement Table S1) with irradiance.

\section{TISSUE STRUCTURE AND CHEMISTRY}

A further analysis of traits underlying SLA can best be done using its inverse, leaf dry mass per unit area (LMA $=1 / \mathrm{SLA}$ ) (Supplement Table S1). LMA can be factorized as the product of leaf thickness and leaf tissue density, for which we used as proxies fresh mass per area and dry mass per fresh mass, respectively. The importance of light-driven variation in leaf thickness and density for variation in LMA is summarized by the numbers shown in Figure 2. Given that the vales of these scaling slope analyses all centered around 0.5 , we concluded that both components were on average equally responsible for the increase of LMA with irradiance. At a given LMA, the leaves of the two shade-tolerant species Geum and Impatiens were relatively thin and had a higher density compared to the three shade-intolerant species. For these two species, the contribution of tissue density to the irradiance effect on LMA was also somewhat larger (Figure 2). The density of stem and/or petiole tissue also increased with irradiance. However, this was not clearly the case for the density of root tissue (Supplement Table S1).

The concentration of organic $\mathrm{N}$ in leaf dry matter $\left(N_{\mathrm{m}}\right)$ was on average $48 \mathrm{mg} \mathrm{g}^{-1}$ and generally not much different between growth irradiances (Supplement Table S2). The N content per leaf area $\left(N_{\mathrm{a}}\right)$, however, increased almost linearly as a result of the similar increase in LMA (Supplement Tables S1, S3). Remarkable is the low $N_{\mathrm{a}}$ of Geum, particularly at high irradiance, which was caused by its low $N_{\mathrm{m}}$. The C-concentration in plant dry matter $([C])$ increased with irradiance and was consistently higher for the shade-tolerant species (Figure 3A). The increase in tissue density with irradiance and shade-tolerance was thus associated with increases in $[C]$ (Figures 2, 3A).

\section{PHOTOSYNTHESIS AND RESPIRATION}

Whole-plant photosynthesis measured at growth irradiance and expressed per unit leaf area $\left(A_{\text {growth }}\right)$ increased almost linearly with increasing irradiance from an average across all species of $1 \mu \mathrm{mol} \mathrm{m} \mathrm{m}^{-2} \mathrm{~s}^{-1}$ at the lowest irradiance to $16 \mu \mathrm{mol} \mathrm{m} \mathrm{m}^{-2} \mathrm{~s}^{-1}$ at the highest (Figure 4A). At the highest irradiance, there was substantial variation between the species, with Geum showing the lowest value $\left(12 \mu \mathrm{mol} \mathrm{m} \mathrm{m}^{-2} \mathrm{~s}^{-1}\right)$ and Helianthus the highest $\left(23 \mu \mathrm{mol} \mathrm{m}^{-2} \mathrm{~s}^{-1}\right)$. Photosynthetic capacity, measured at the leaf level as the light-saturated rate of photosynthesis per unit leaf area $\left(A_{\text {sat }}\right)$ also increased with growth irradiance (Figure 4B). $A_{\text {sat }}$ was higher than $A_{\text {growth }}$ at all light levels, increasing from on average 5 to $25 \mu \mathrm{mol} \mathrm{m}{ }^{-2} \mathrm{~s}^{-1}$. Only Geum grown at the highest irradiance had similar values for $A_{\text {sat }}$ and $A_{\text {growth }}\left(12 \mu \mathrm{mol} \mathrm{m}^{-2}\right.$ $\mathrm{s}^{-1}$; Figure 4).

$A_{\text {growth }}$ expressed per unit shoot dry mass $\left(A_{\mathrm{m}}\right)$ showed a qualitatively similar curvilinear response to irradiance as RGR, with a strong increase in the lower range but less so in the higher 


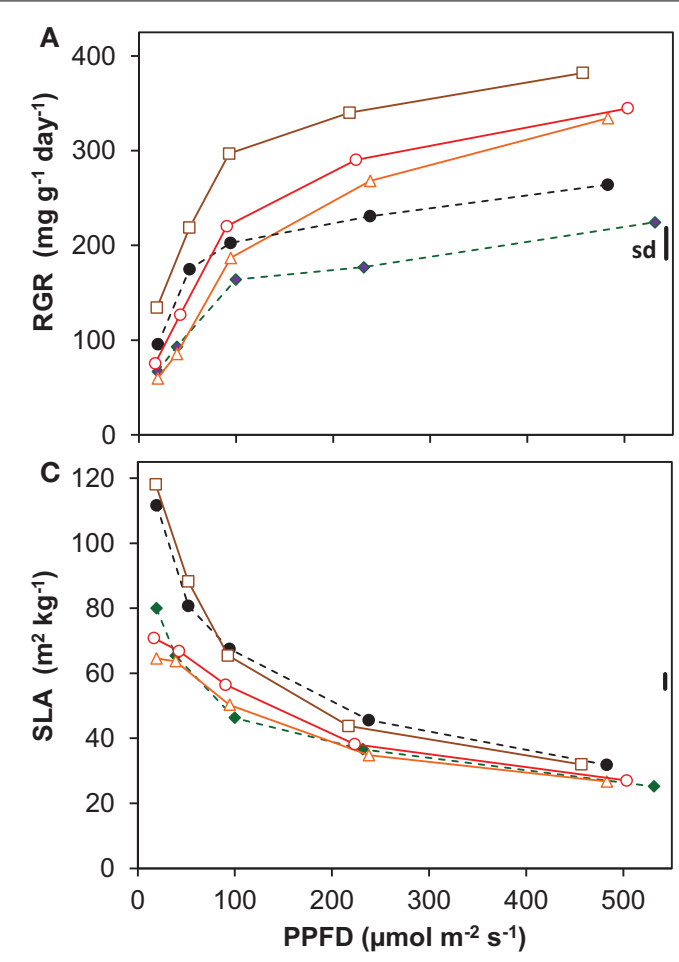

FIGURE 1 | Growth variables of five species grown at five irradiance levels (Photosynthetic photon Flux Density; PPFD). (A) Relative Growth Rate (RGR, dry mass increase per unit plant mass and time); (B) Unit Leaf Rate (ULR, dry mass increase per unit leaf area and time); (C) Specific Leaf Area (SLA, leaf area per unit leaf dry mass); (D) Leaf Mass Fraction (LMF, leaf mass per unit plant mass) and Root Mass Fraction (RMF). Means are shown

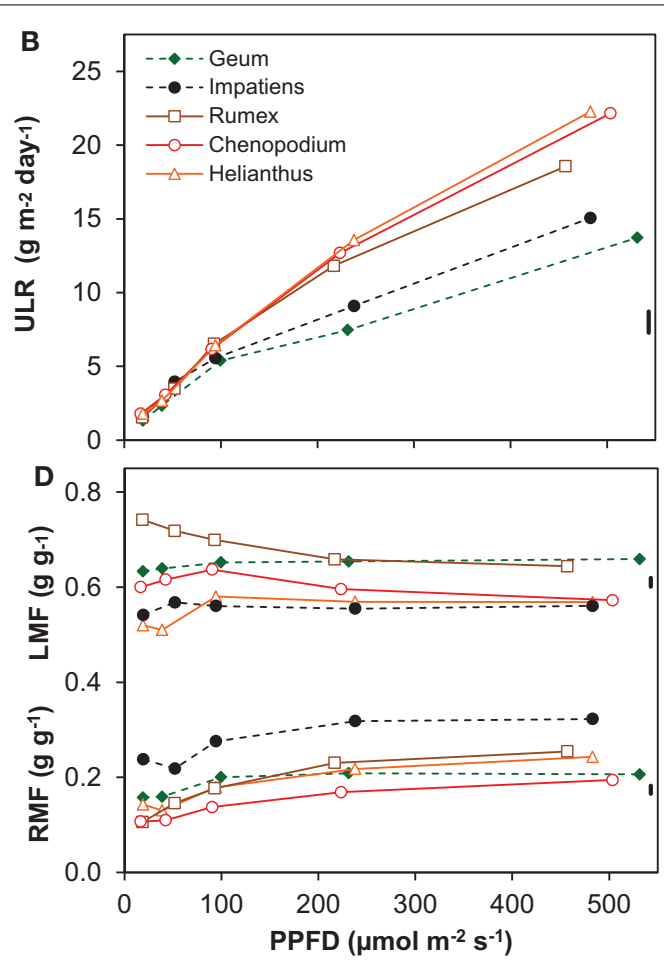

( $n=8$ ). The vertical bars at the right of each panel show the common standard deviation (sd), which was calculated as the mean coefficient of variation multiplied by the overall mean and positioned in the panel at the overall mean value of that variable. Continuous lines with open symbols indicate shade-intolerant species, broken lines with closed symbols shade-tolerant ones. range (Figure 5A). Shoot $R_{\mathrm{m}}$ also increased with irradiance and was on average $17 \%$ of shoot $A_{m}$ (Figures 5A,B). However, the relative increase in shoot $R_{\mathrm{m}}$ between the lowest and the highest irradiance was only about 3 -fold, whereas shoot $A_{\mathrm{m}}$ increased about 6-fold (Figures 5A,B). Consequently, the instantaneous shoot $R / A$ ratio decreased with increasing irradiance (Figure 5D).

Root $R_{\mathrm{m}}$ was successfully measured across the full range of growth irradiances for Helianthus and Geum only. For the other species data are available for just part of the light range. Averaged over species and conditions, root $R_{\mathrm{m}}$ was on average 2.9 times higher than shoot $R_{\mathrm{m}}$. Helianthus showed a gradual increase of root $R_{\mathrm{m}}$ with irradiance, but Geum, and also Impatiens for which data are available for most of the range, were rather constant across most of the light range, with lower values at the lowest irradiance only (Figure 5C).

Daily whole-plant R/A of Helianthus and Geum, for which the $R_{\mathrm{m}}$ data are available for the full range, showed a tendency to increase with decreasing irradiance. However, there was a significant difference in irradiance dependence between the two species (Table 2). In Helianthus $R / A$ increased relatively strongly below an irradiance of $100 \mu \mathrm{mol} \mathrm{m} \mathrm{m}^{-2} \mathrm{~s}^{-1}$, to 0.51 at $20 \mu \mathrm{mol} \mathrm{m}^{-2} \mathrm{~s}^{-1}$, whereas Geum showed a more stable daily $R / A$, increasing to only 0.33 at $20 \mu \mathrm{mol} \mathrm{m}^{-2} \mathrm{~s}^{-1}$ (Figure 5F). Taking also the available data for the other species into account, the evidence points to a rather stable $R / A$ of about 0.3 on average across a large part of the irradiance gradient with a tendency to increase only at the lowest irradiance (Figure 5E). In relative terms, the C-balance was therefore essentially constant across a large part of the growth irradiance gradient (Figure 5F). In absolute terms, however, the C-balance showed an increasing positive difference between $A$ and $R$ with irradiance.

\section{DISCUSSION \\ GROWTH AT HIGHER IRRADIANCES}

For the five species investigated in this experiment, the general form of the irradiance response for RGR and its components was similar to what has been reviewed in for example Poorter and van der Werf (1998), with the exception that RGR did not fully saturate at $20 \mathrm{~mol} \mathrm{~m}^{-2} \mathrm{day}^{-1}$. The latter phenomenon is often reported for shade-tolerant species, such as Impatiens (Evans and Hughes, 1961; Corré, 1983a) and Geum (Blackman and Wilson, 1951; Corré, 1983a). In the high-light range shadetolerant species may even show decreases in RGR (Huxley, 1967; Veenendaal et al., 1996; Poorter, 1999). Growth experiments in an irradiance gradient generate large differences in demand for water and nutrients (Poorter et al., 2012a). A lack of increase or even a decrease in RGR at the high irradiance end in pot-grown plants could therefore be a secondary effect of limitations in the root environment, rather than a result of an intrinsic character of the species. Indeed, a saturated RGR across the high irradiance range was also observed for Geum in an outdoor experiment where watering of the plants was not optimal, whereas replication of 
Table 2 | Two-Way ANOVA for the variables shown in the figures.

\begin{tabular}{|c|c|c|c|c|c|c|c|}
\hline Variable & Species & PPFD & Spec X PPFD & Tol vs. intol & Tol vs.-intol X PPFD & Total $d f$ & $r^{2}$ \\
\hline \multicolumn{8}{|l|}{ Figure 1} \\
\hline RGR & $18 * * *$ & $76 * * *$ & $6 * * *$ & $24 * * *$ & $26 * * *$ & 199 & 0.89 \\
\hline ULR & $2 * * *$ & $96 * * *$ & $2 * * *$ & $71 * * *$ & $100 * * *$ & 199 & 0.94 \\
\hline SLA & $10 * * *$ & $87 * * *$ & $2 * * *$ & $1 *$ & $23 * * *$ & 199 & 0.96 \\
\hline LMF & $84 * * *$ & $2 * * *$ & $14 * * *$ & $1 * * *$ & $15 * * *$ & 199 & 0.88 \\
\hline RMF & $47 * * *$ & $46 * * *$ & $7 * * *$ & $53 * * *$ & $60 * * *$ & 199 & 0.92 \\
\hline \multicolumn{8}{|l|}{ Figure 2} \\
\hline LMA & $9 * * *$ & $88 * * *$ & $3 * * *$ & $0^{\text {ns }}$ & $21 * * *$ & 199 & 0.94 \\
\hline Leaf density & $73 * * *$ & $26 * * *$ & $1 * * *$ & $55^{* * *}$ & $45 * * *$ & 199 & 0.98 \\
\hline Leaf thickness & $67 * * *$ & $31 * * *$ & $2 * * *$ & $86 * * *$ & $10^{+}$ & 199 & 0.96 \\
\hline \multicolumn{8}{|l|}{ Figure 3} \\
\hline$[C]$ (plant) & $59 * * *$ & $34 * * *$ & $6 * *$ & $91 * * *$ & $11^{\mathrm{ns}}$ & 49 & 0.94 \\
\hline CC (plant) & $65 * * *$ & $29 * * *$ & $6^{+}$ & $90 * * *$ & $10^{\text {ns }}$ & 49 & 0.92 \\
\hline \multicolumn{8}{|l|}{ Figure 4} \\
\hline$A_{\text {growth }}$ (plant) & $4 * * *$ & $89 * * *$ & $6 * * *$ & $1 * * *$ & $2 * * *$ & 195 & 0.95 \\
\hline$A_{\text {sat }}$ (leaf) & $21 * * *$ & $76 * * *$ & $3 * * *$ & & & 68 & 0.97 \\
\hline \multicolumn{8}{|l|}{ Figure 5} \\
\hline$A_{m}$ (shoot) & $14 * * *$ & $79 * * *$ & $8 * * *$ & $4 * *$ & $38 * * *$ & 195 & 0.91 \\
\hline$R_{\mathrm{m}}$ (shoot) & $13 * * *$ & $78 * * *$ & $9 * * *$ & $0^{\text {ns }}$ & $35 * * *$ & 194 & 0.88 \\
\hline$R_{\mathrm{m}}$ (root) & $3^{+}$ & $89 * * *$ & $8^{+}$ & & & 60 & 0.62 \\
\hline Inst. $R / A$ (shoot) & $21 * * *$ & $63 * * *$ & $16 * * *$ & $29 * * *$ & $63 * * *$ & 194 & 0.66 \\
\hline Daily $R / A$ (calc.) & $14 * * *$ & $33 * * *$ & $53 * * *$ & $5^{\text {ns }}$ & $23^{* *}$ & 194 & 0.38 \\
\hline Daily $R / A$ (meas.) & $7 *$ & $79 * * *$ & $14 *$ & & & 60 & 0.57 \\
\hline
\end{tabular}

The 1st, 2nd, and 3rd columns after the variable names show the percentages of explained variance that is due to the effect of Species, growth irradiance (PPFD) and the interaction of the two. The 4th and 5th column show the explained variance of the a-priori contrasts of shade-tolerant (Tol) vs shade-intolerant (Intol) species for the Species main effect and the Species $\times$ PPFD interaction. The percentages refer to explained variance relative to the Species and Species $\times$ PPFD effect, respectively. The last two columns indicate the degrees of freedom and the adjusted $r^{2}$ of the full model. Significance levels: $n s$, non-significant; $+0.05<P<0.10$; ${ }^{*} P<0.05 ;{ }^{*} P<0.01 ;{ }^{* *} P<0.001$. The effects that absorb more than $50 \%$ of the sum of squares explained by the main and interaction effects of the model are indicated in bold. Note that the root $R_{m}$ and the measured daily $R / A$ whole-plant values are based on Helianthus and Geum only, and that the contrasts in shade tolerance were not tested for $A_{\text {sat }}$ measured at the leaf level (leaf) because the data for Geum were not complete.

the experiment with ample water supply resulted in an increasing RGR up to full daylight (Pons, 1977a), similar to what was found here (Figure 1A).

In their meta-analysis, Poorter and van der Werf (1998) showed a predominance of SLA in explaining species specific variation in RGR for herbaceous plants, and this was also the case among the three shade-intolerant species, with Rumex showing the fastest growth and highest SLA at each irradiance level (Figures 1A,C). However, at higher irradiances the result is strongly different when we include the shade-tolerant species: in that case, variation in ULR is the dominant variable that scales with interspecific variation in RGR. The evidence is summarized in Figure 6A, where we calculated the so-called GRC. These GRC values indicate how much the variation in RGR scales with variation in the multiplicative components of equation 2 in Appendix 1 (Renton and Poorter, 2011). They can be used to summarize in a highly efficient way what the relative importance is for each of the components in causing the variation in RGR. A GRC value for ULR of 0 , for example, would indicate RGR increases without a concomitant increase in ULR, whereas a value of 1 would imply that a $10 \%$ increase in RGR goes with a $10 \%$ increase in ULR. In our experiment, the GRC values for SLA and LMF decrease with increasing irradiance, whereas the GRC for the ULR rises from
0 to 0.8 , indicating that the higher the irradiance, the stronger interspecific variation in RGR is determined by ULR differences. A similar response was found in the meta-analysis of Shipley (2006), who included both herbaceous and woody species, of which several were shade-tolerant. In other studies with herbaceous species-using partly the same shade-tolerant species as the present experiment-a lower ULR in conjunction with a lower RGR compared to their shade-intolerant counterparts was also found (Pons, 1977a; Corré, 1983a). Similar results were reported for tropical trees, where the differences in RGR at higher irradiances were due to the low ULR of shade-tolerant species as well (Veneklaas and Poorter, 1998; Poorter, 1999). However, when the GRC-analysis is restricted to the three shade-intolerant species, the SLA is much more important for explaining differences in RGR at high irradiance (Figure 6B; Poorter and van der Werf, 1998). Clearly, the ecological background of species included in the comparison is important for the conclusion whether variation in assimilation rate or allocation and morphology are important for explaining interspecific variation in RGR. This is particularly an issue when shade-tolerant species grown at high irradiance are included in the comparison.

The low ULR of Geum at the highest irradiance is associated with a low $A_{\text {growth }}$ (Figures 1B, 4A). Its $A_{\text {sat }}$ was only slightly 


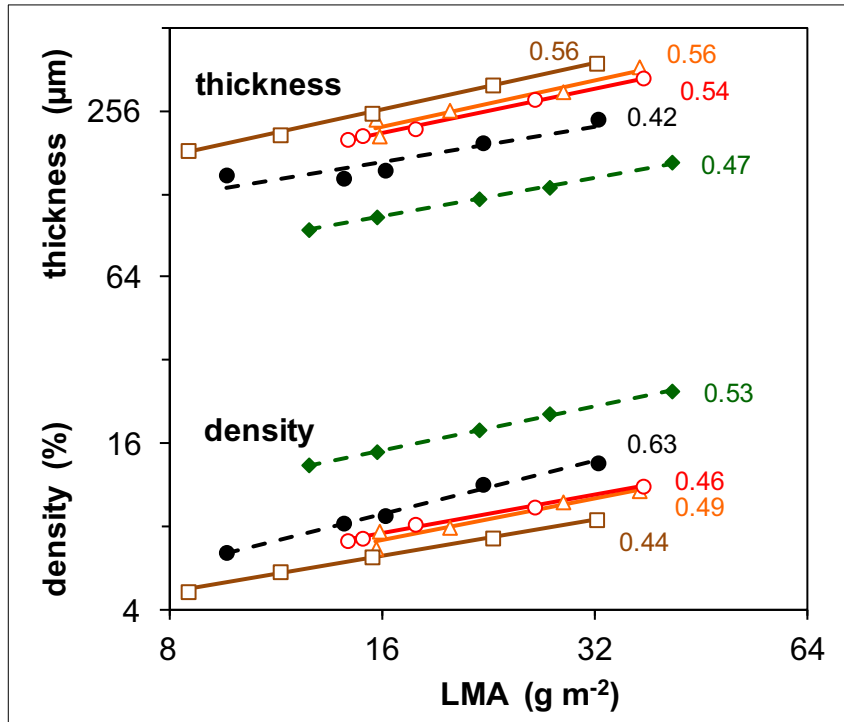

FIGURE 2 | Changes in leaf tissue density and thickness associated with the changes in leaf dry mass per area (LMA) as induced by different irradiance levels. Data are given for five species and are average values pertaining to all leaves of the plant. The regression coefficients from a scaling slope analysis, quantifying the fractional contribution of leaf density and thickness to variation in LMA given to the right of the lines. LMA is the inverse of SLA shown in Figure 1C. Mean values $(n=8)$ of density and thickness were log-transformed and plotted against log-transformed LMA. For symbols see Figure 1. The values of LMA, tissue density and leaf thickness are given in Supplement Table S1. For further explanation of the scaling slope analysis see text.

higher, thus $A_{\text {growth }}$ was limited by its low photosynthetic capacity (Figure 4B, Supplement Table S3). Why do shade species often have a low photosynthetic capacity when grown at high irradiance? Geum is known to form only a single layer of palisade parenchyma (Pons, 1977a), which limits the development of a high $A_{\text {sat }}$ (Terashima et al., 2001). A lack of the capability to develop a multilayered palisade parenchyma was also reported for Impatiens together with a relatively low photosynthetic capacity (Groen, 1973). Although Impatiens had not a particularly low $A_{\text {sat }}$ in our experiment it did not increase in the highest irradiance interval (Figure 4B). A single layer of palisade parenchyma and/or a low photosynthetic capacity in high-irradiance grown shade-tolerant plants is often reported, such as in temperate herbaceous species (Osborne et al., 1994; Murchie and Horton, 1997), tropical herbaceous plants (Chow et al., 1988), tropical shrubs (Valladares et al., 2000), temperate deciduous trees (Jackson, 1967; Hanba et al., 2002) and tropical trees (Houter and Pons, 2012). Shade-intolerant species, on the other hand, generally develop multilayered palisade parenchyma at high irradiance, which is associated with their high photosynthetic capacity (Jackson, 1967; Groen, 1973; Pons, 1977a; Hanba et al., 2002). We therefore conclude that one of the likely reasons for the low photosynthetic capacity at high growth irradiance in shade-tolerant species is their incompetence to develop a multilayered palisade parenchyma.

A very high $A_{\text {sat }}$ of $34 \mu \mathrm{mol} \mathrm{m} \mathrm{m}^{-2} \mathrm{~s}^{-1}$ at the leaf level was indeed found for Chenopodium grown at the highest
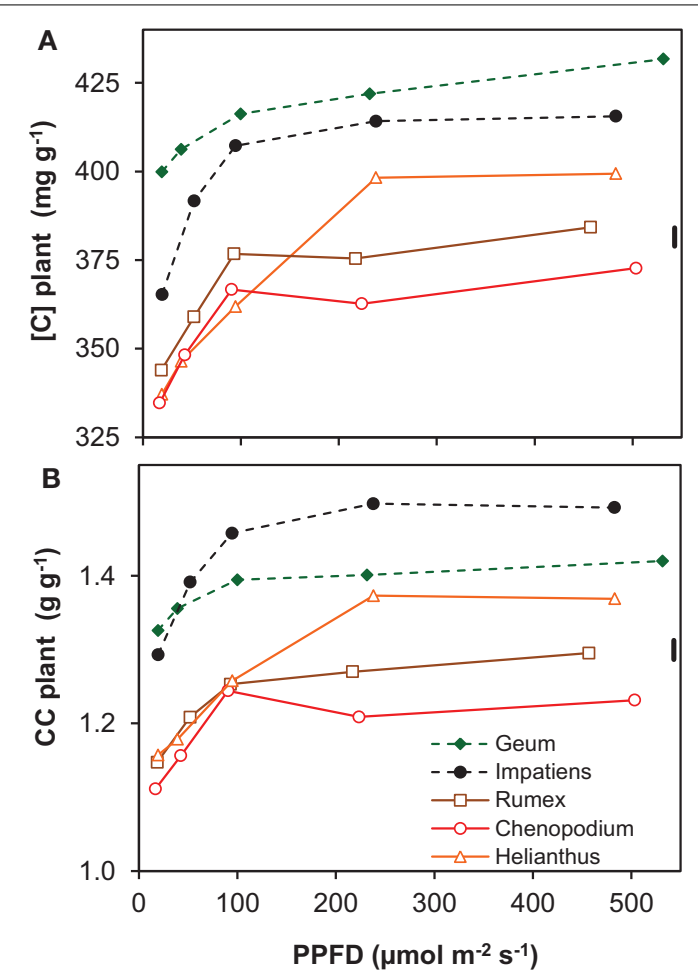

FIGURE 3 | Chemical composition of whole-plant dry matter of five species grown at five irradiance levels (PPFD). (A) Carbon concentration in whole-plant dry matter ([C]); (B) construction costs (CC) of whole-plant dry matter calculated from the chemical composition. Means ( $n=2$ bulk samples) and the common standard deviation (sd) are shown. The chemical composition from which the CC was derived is shown in Supplement Table S2.

irradiance (Figure 4B), as was reported elsewhere (Sage and Pearcy, 1987). Such a high $A_{\text {sat }}$ was also reported for Helianthus (e.g., Fredeen et al., 1991). We found a lower value at the highest irradiance than expected, which is likely due to the rather low $N_{\mathrm{m}}$ of the leaves used for the $A_{\text {sat }}$ measurements. This was not representative for the plants used for the whole-plant gas exchange (Figure 4, Supplement Tables S1-S3). The high $A_{\text {sat }}$ of Chenopodium and supposedly also Helianthus facilitated the high $A_{\text {growth }}$ (Figure 4A) and as $A_{\text {growth }}$ is strongly related to ULR (Figure 7), also the latter. However, it should be noted that the high $A_{\text {sat }}$ of the shade-intolerant species is not fully utilized in the growth conditions with a constant relatively low irradiance during daytime. Chenopodium and Helianthus had a low investment of leaf $\mathrm{N}$ per unit $A_{\text {sat }}$ compared to Geum, and thus a high photosynthetic nitrogen use efficiency (PNUE sat $_{\text {; }}$ Supplement Table S3). However, as their $A_{\text {sat }}$ is not fully utilized, the PNUE of the species was similar at the growth irradiance (Supplement Tables S1, S3). In field conditions, highlight exposed plants experience widely fluctuating irradiance often exceeding saturation. A high $A_{\text {sat }}$ is then utilized to a much larger extent and correlates better with daily assimilation (Zotz and Winter, 1993). Larger differences in daily assimilation and consequently ULR between species with different $A_{\text {sat }}$ may thus be expected at variable irradiance as in field conditions 

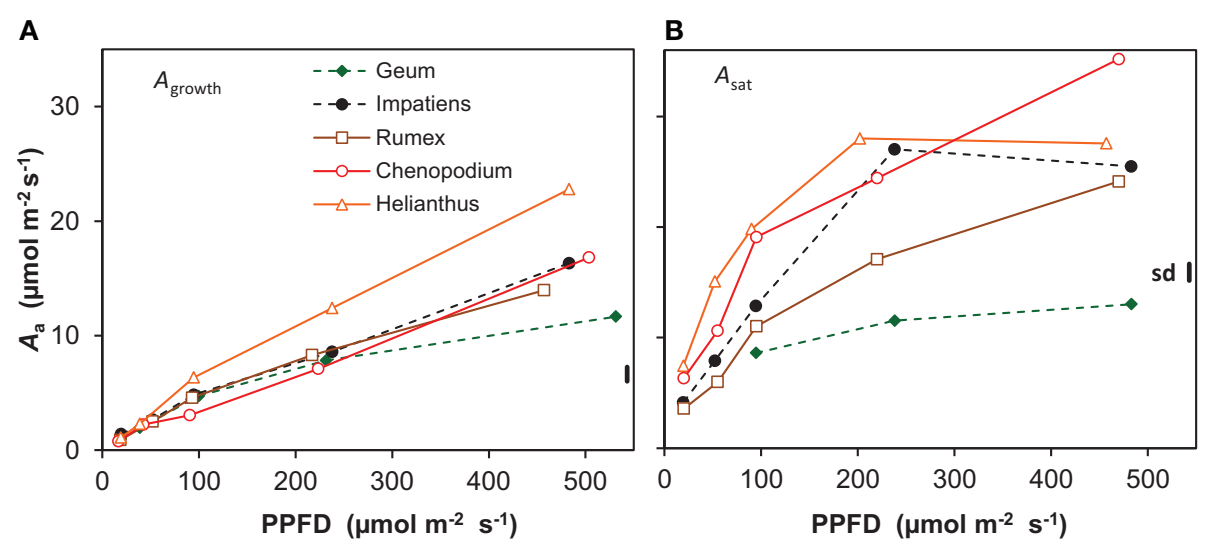

FIGURE 4 | Photosynthesis per unit leaf area $\left(A_{a}\right)$ of five species grown at five irradiance levels (PPFD). (A) Net photosynthesis per unit leaf area of whole shoots measured at growth irradiance $\left(A_{\text {growth }}\right)$; (B) light-saturated rate of photosynthesis per unit leaf area $\left(A_{\text {sat }}\right)$ measured on recently matured leaves. Means ( $n=8$ and $n=3$ for $A_{\text {growth }}$ and $A_{\text {sat }}$, respectively) and the common standard deviation (sd) are shown.
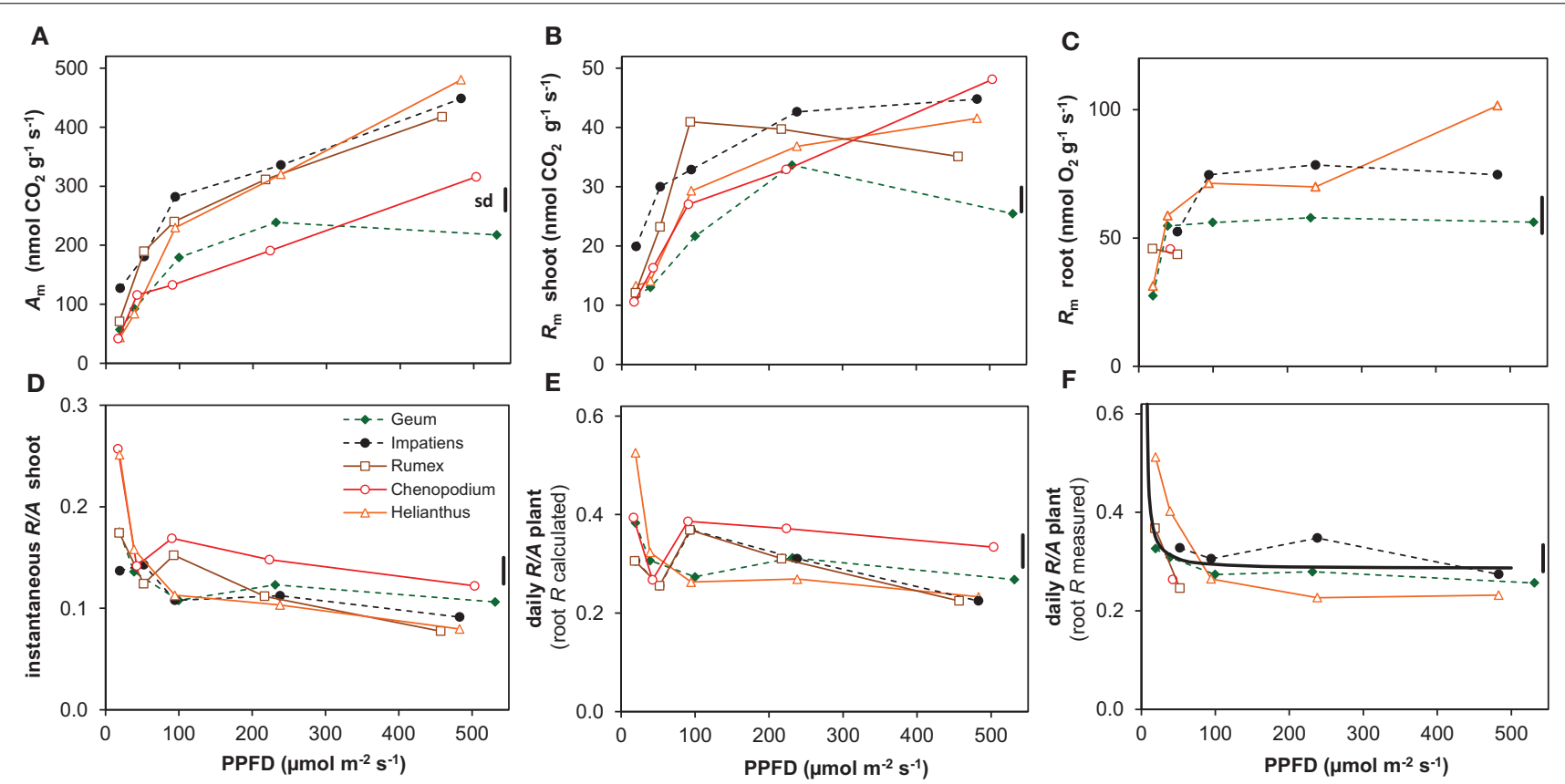

FIGURE 5 | Photosynthesis $(A)$ and respiration $(R)$ and the ratio between the two $(R / A)$ of the five species grown at different irradiances (PPFD).

(A) Rates of net $\mathrm{CO}_{2}$ assimilation at the growth irradiance of whole shoots per unit shoot dry mass $\left(A_{\mathrm{m}}\right)$; (B) release of $\mathrm{CO}_{2}$ in darkness of whole shoots per unit shoot dry mass (dark respiration; $R_{\mathrm{m}}$ ); (C) root respiration measured as the rate of $\mathrm{O}_{2}$ consumption per unit root dry mass $\left(R_{\mathrm{m}}\right)$; (D) shoot $R / A$ ratio on an instantaneous basis; (E) whole-plant daily $R / A$ ratio using root $R$ calculated from shoot $R$ (root $R=2.9 \times$ shoot $R$ ); (F) whole-plant daily $R / A$ ratio based on measured root $R$ for the species and irradiances for which root $R$ was available. Shown are the means $(n=8)$ and the average standard deviation (sd). The solid line in $(\mathbf{F})$ depicts the simulated $R / A$ ratio as explained in the text. compared to the constant light regime often used in growth rooms.

\section{GROWTH AT THE LOWER IRRADIANCES}

At the lower irradiances, the differences in RGR between species are more determined by differences in SLA-and to a lesser extent LMF-than by ULR (Figure 6A). Such a predominance of variation SLA for explaining species specific differences in RGR at low irradiance was more often reported (Veneklaas and Poorter, 1998; Shipley, 2006). This can be explained by the strong light limitation of photosynthesis at low irradiance resulting in a more similar $A_{\text {growth}}$, which is also evident in our data (Figure 4A). A higher SLA is then of crucial importance for increased growth.

Contrary to the situation at high irradiance, we did not observe a systematic difference of RGR between shade-tolerant and shade-intolerant species at low irradiance (Figure 1A, Supplement Table S2). Chenopodium and Helianthus showed little further increase of SLA with decreasing irradiance (Figure 1C). This lack of competence to develop a high SLA at low irradiance was earlier reported for Helianthus (Hiroi and Monsi, 1963) 

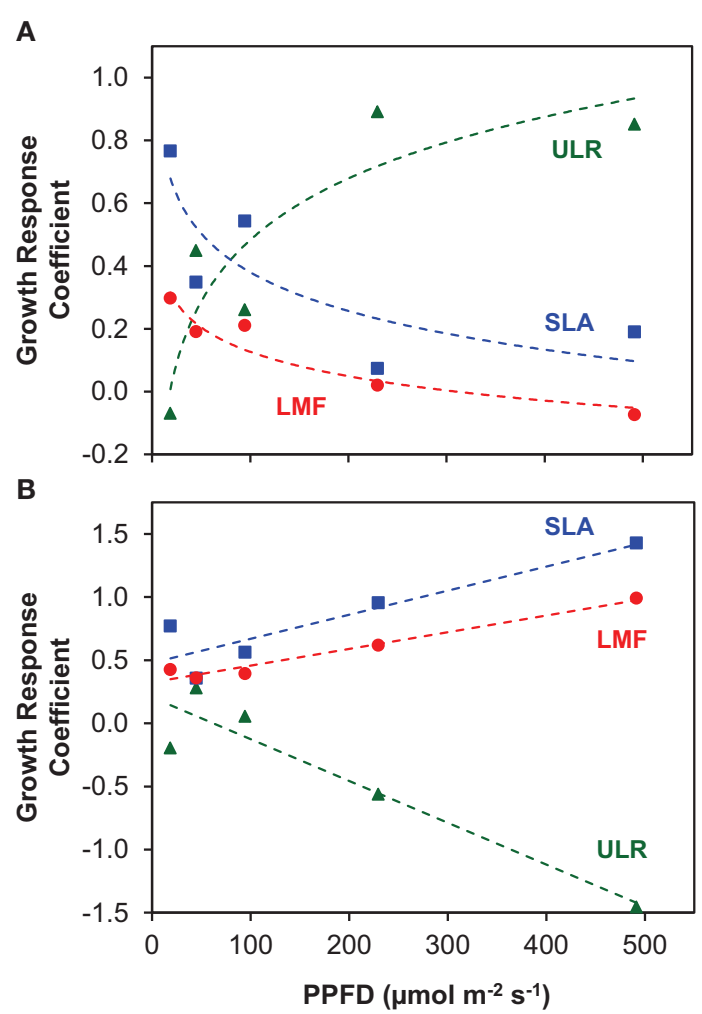

FIGURE 6 | The Growth Response Coefficients (GRC), showing the contribution of variation in the components ULR, SLA and LMF to variation in RGR for interspecific comparisons at each growth irradiance (PPFD). (A) All species included in the analysis; (B) analysis for the three shade-intolerant species only. The regression coefficients of log-transformed ULR, SLA and LMF on log-transformed RGR at each growth irradiance represent the GRC's.

and also for the shade-intolerant Cirsium palustre (Pons, 1977a). Helianthus and Chenopodium may thus show a stronger decrease in net C-gain when the trend continues with a further decrease in irradiance compared to species that are able to increase their SLA further.

\section{TISSUE STRUCTURE AND CHEMISTRY}

There was no evidence for important differences between the shade-tolerant and intolerant species in acclimation to irradiance at the chloroplast level, as derived from the chlorophyll a/b ratio and photosynthesis per unit chlorophyll (Supplement Table S3). However, at the leaf level, anatomical leaf traits are likely to make acclimation different between species, as discussed above.

Although a low LMA (and thus a high SLA) maximizes growth potential at low irradiance (Evans and Poorter, 2001), it does not necessarily increase fitness. A low LMA can weaken the leaves (Onoda et al., 2008), which may reduce leaf longevity and therefore diminish return on carbon investment (Lusk et al., 2008). A higher LMA would increase longevity when based on investment in defense components such as lignin and tannins (Lusk and Warton, 2007; Kitajima et al., 2013). However, the relatively high LMA of Helianthus and Chenopodium at low irradiance (Figure 1C) is associated with a relatively high $A_{\text {sat }}$

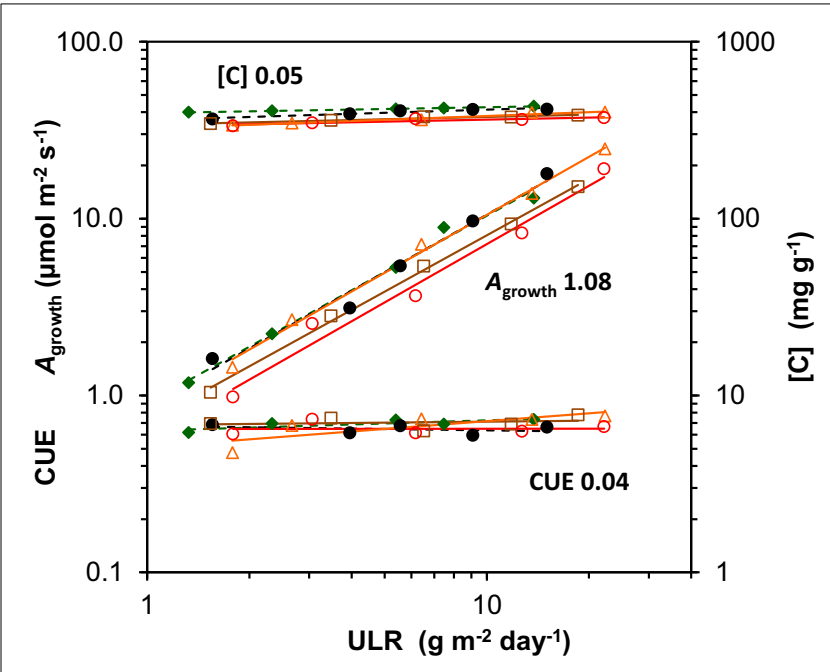

FIGURE 7 | Scaling slope analysis for each species of the contribution of its components to variation in unit leaf rate (ULR) across growth irradiances. The components are whole-plant gross photosynthesis per unit leaf area at the growth irradiance $\left(A_{\text {growth }}\right)$, whole-plant $\mathrm{C}$-concentration ([C]) and the carbon use efficiency (CUE), the fraction of daily assimilated $C$ invested in biomass (CUE $=1-R / A$ ). The means were log-transformed and plotted against log-transformed ULR. The mean across species of the regression coefficients per component, depicting the average fractional contributions, are shown next to the regression lines. As the net assimilation rate calculated from gas exchange (NAR ge $=A_{\text {growth }}$ CUE/[C]) is not necessarily fully identical with ULR, the fractional contributions ( $A_{\text {growth }}$ and CUE positive, and $[C]$ negative) do not exactly add up to unity. Species are identified by their markers and regression lines (for the legend see Figure 1).

(Figure 4B, Supplement Tables S1, S3) and thus a relatively large investment in protein-rich chloroplasts. Similar to the situation at high irradiance, the high $A_{\text {sat }}$ of these species grown at low irradiance was also not utilized in the growth conditions, resulting in a low PNUE growth (Supplement Tables S1, S3). Such shade leaves with a relatively high $N_{\mathrm{a}}$ (Supplement Tables S1, S3) can furthermore be attractive for herbivores. It is thus not likely that the high LMA of these species would add to their leaf longevity in shade, but rather makes them inefficient and vulnerable under these conditions.

The construction costs of plant tissue increased with irradiance (Figure 3B). This was mainly the result of lower concentrations of minerals in the dry matter, including nitrate (Supplement Table S2). The $[C]$ increased for the same reason (Figure 3A). The clearly higher construction costs and $[C]$ of the shade-tolerant species compared to the shade-intolerant ones (Figure 3) was not only due to lower mineral and nitrate concentrations, but also to a lower organic acid concentration in their dry matter (Supplement Table S2). These traits of the shade-tolerant species were in turn associated with high density of leaf tissue (Figure 2) and-in the case of Geum - also of petioles and roots (Supplement Table S1). They could, in the case of Geum including a low $N_{\mathrm{m}}$, be associated with better defense resulting in increased leaf longevity in shade. This is important at low irradiance, as photosynthetic rates are inherently low. The time that it takes to generate the construction costs (pay-back time) is therefore unavoidably longer (Poorter et al., 2006). The high construction costs and [C] of 
the shade-intolerant species are at the expense of RGR (equation 1 ), but when these traits do indeed increase longevity, they are essential for survival in shade.

\section{THE CARBON BALANCE}

The growth parameter ULR can be factorized into $A_{\text {growth }}$, CUE $(=1-R / A)$ and the $[C]$ (equation 3 in Appendix 1). Using the same scaling slope analysis as explained above for the GRC, we can quantitatively asses the relative importance of variation in each of these components. The analysis shows that $A_{\text {growth }}$ scaled linearly and strongly with ULR when irradiance increases, with an average slope across species close to 1.0 (Figure 7). Variation in $R / A$ and $[C]$ contributed little to variation in ULR (Figures 3A, 5E,F, 7). The growth calculated on the basis of gas exchange $\left(\mathrm{NAR}_{\mathrm{ge}}\right)$ was on average $11 \%$ higher than from harvest data (ULR). A small difference is not surprising as $A_{\text {growth }}$ and $R$ measured at one moment in time are not necessarily fully representative for the rates over the whole experimental period. Nevertheless, it shows that for juvenile plants grown at various light levels, ULR can be an effective estimator of photosynthesis under growth conditions.

Photosynthesis also increased proportionally with growth rate when both variables are expressed per unit dry mass (resp. $A_{\mathrm{m}}$ and RGR) (Figure 8A). Although $R_{\mathrm{m}}$ of both shoots and roots increased linearly with RGR as well, it did not scale fully proportionally with RGR as a result of the positive $y$-intercept (Figures 8B,C). This intercept, $R_{\mathrm{m}}$ at zero growth, is considered to be an estimate of the maintenance respiration. The part that is proportional to RGR represents the growth-related respiration (Lambers et al., 2002). From the relationships of $A_{\mathrm{m}}$ and $R_{\mathrm{m}}$ with RGR (Figure 8) it would follow that the $R / A$ ratio should decrease with increasing RGR and thus with irradiance. That was indeed found for the instantaneous values as measured on shoots (Figure 5D). However, as root $R_{\mathrm{m}}$ was found to be 2.9 times higher than shoot $R_{\mathrm{m}}$ (Figures 5B,C), the decrease in RMF with decreasing irradiance (Figure 1D) has a diminishing effect on daily whole-plant $R$, which explains the relatively constant daily whole-plant $R / A$ ratio across a broad range of irradiances (Figures 5E,F). Adjustments of whole-plant $R$ can quickly occur when $A$ changes after transfer to another irradiance (McCree and Troughton, 1966; Pons, 1977b), probably as a result of altered demand for ATP (Noguchi et al., 2001). The adjustments are apparently such that whole-plant $R / A$ remained more or less constant at around 0.3 across a wide range of irradiances.

The situation is somewhat different at light levels close to the light compensation point. At $20 \mu \mathrm{mol} \mathrm{m}{ }^{-2} \mathrm{~s}^{-1}, R / A$ showed a tendency to be higher than at the other irradiances (Figure $5 F$ ). As the data set for root $R_{\mathrm{m}}$ is incomplete, we estimated $R / A$ in two other ways. In the first, we assumed root $R_{\mathrm{m}}$ to be 2.9 times higher than the shoot $R_{\mathrm{m}}$, which is the average of the measurements. Shoot $R_{\mathrm{m}}$ is available for all species and irradiances and $R / A$ calculated in this way thus also (Figure 5E). In the second we calculated daily whole-plant $R / A$ from the linear relationship of $A_{\mathrm{m}}$, and shoot and root $R_{\mathrm{m}}$ with RGR (Figure 8), and the linear relationship of RGR and RMF with log-transformed irradiance for all species together (Supplement Figure S1). In both cases the outcome was an almost constant $R / A$ with indeed increasing values below about $50 \mu \mathrm{mol} \mathrm{m} \mathrm{m}^{-2} \mathrm{~s}^{-1}$ (black continuous line in Figure 5F). Extrapolation of the relationships yielded an $R / A$

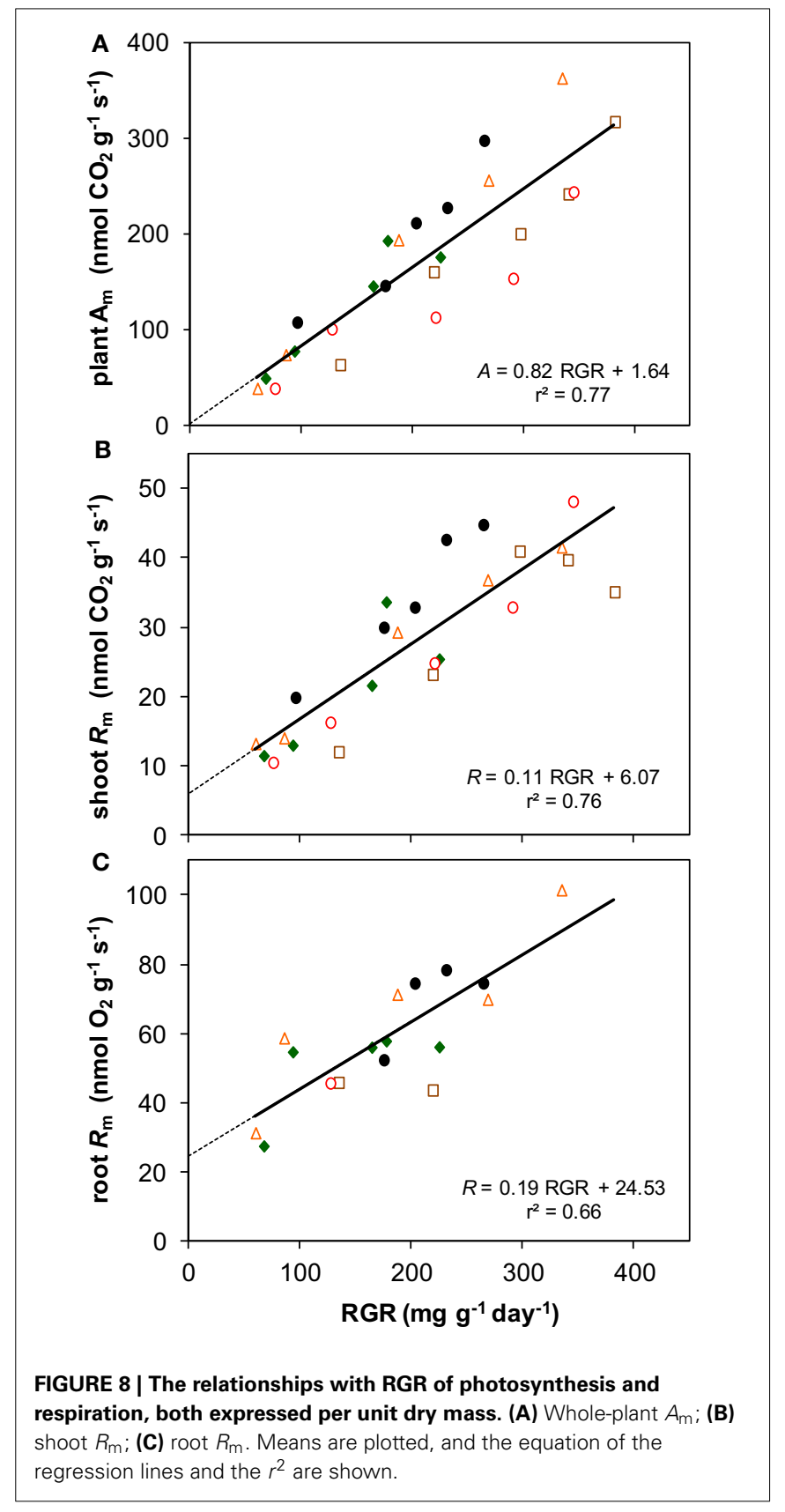

of unity (i.e., the whole-plant light compensation point sensu Givnish (1988) at an irradiance of $6 \mu \mathrm{mol} \mathrm{m} \mathrm{m}^{-2} \mathrm{~s}^{-1}(0.35 \mathrm{~mol}$ $\left.\mathrm{m}^{-2} \mathrm{day}^{-1}\right)$. This value is higher than the measured light compensation points for growth reported by Mahmoud and Grime (1974) and Pons (1983), which were 3.2 and $1.7 \mu \mathrm{mol} \mathrm{m}^{-2} \mathrm{~s}^{-1}$, respectively. Our calculation assumes a constant maintenance respiration at all irradiances. The fact that lower compensation points were measured than calculated suggests that the assumption that maintenance respiration remains constant is not correct. Alternatively, maintenance respiration may be down-regulated at very low irradiances, as is also found after longer periods in darkness (Gifford, 2003).

A constant $R / A$ was found for Pisum sativum between 100 and $400 \mu \mathrm{mol} \mathrm{m} \mathrm{m}^{-2} \mathrm{~s}^{-1}$ (McCree and Troughton, 1966), and Holcus lanatus and Plantago major at 150 and $300 \mu \mathrm{mol} \mathrm{m}^{-2} \mathrm{~s}^{-1}$ 
(Poorter, 2002). When calculated from shoot $A$ and $R$ data from Pons (1977a), assuming the same 2.9-fold higher root $R_{\mathrm{m}}$ than shoot $R_{\mathrm{m}}$, whole-plant $R / A$ was also largely constant between 5 and $100 \%$ full daylight in Geum urbanum. In conjunction with previous observations, we therefore conclude that-with the exemption of very low light levels - the growth dependence of $R_{\mathrm{m}}$ and the decreasing RMF can establish a stable whole-plant $R / A$ across a broad range of growth irradiances.

A conservative $R / A$ ratio was also found when plants were grown at different temperatures in the range that plant normally encounter in their natural habitat (Gifford, 1995; Loveys et al., 2002). Whole-plant $R$ and $A$ acclimated to the growth temperature within this range, but higher temperatures caused an increase in $R / A$ as a result of increasing $R$ and decreasing $A$ (Atkin et al., 2007). Elevated $\mathrm{CO}_{2}$ also has only marginal effects on the $R / A$ ratio (Poorter, 2002; Gifford, 2003). However, a decrease in nutrient availability caused an upward shift in $R / A$ (van der Werf et al., 1992; Poorter et al., 1995). This was the result of a strong increase in RMF, in combination with the fact that roots have a so much higher $R$ than shoots. Hence, plants tend to maintain a homeostatic $R / A$ ratio when irradiance temperature and $\mathrm{CO}_{2}$ vary, but $R$ increases relative to $A$ when nutrient availability declines as costs for nutrient acquisition increase.

\section{INTERSPECIFIC VARIATION IN C-BALANCE}

Are there species-specific differences in the C-balance at low irradiance? And are these associated with shade-tolerance? Reliable measurements of root $R_{m}$ across the whole range of irradiances are available for only two species, the shade-tolerant Geum and the intolerant Helianthus (Figure 5C). Geum had a more stable $R / A$ than Helianthus, which showed a strong increase in $R / A$ at the lowest irradiance (Figure 5F, Table 2). However, the available data points at low irradiance for the other species do not support a systematic difference between shade-tolerant and intolerant species (Figure 5F). The $R / A$ at the shoot level shows higher values for Helianthus and Chenopodium at low irradiance (Figure 5D) and so does the whole-plant $R / A$ based on shoot $\mathrm{R}_{\mathrm{m}}$ measurements only (Figure $5 \mathrm{E}$ ). The differences are significant for the shade-tolerant-shade-tolerant contrast (Table 2), but the growth analysis data do not show clear evidence of reduced net C-gain at $20 \mu \mathrm{mol} \mathrm{m}{ }^{-2} \mathrm{~s}^{-1}$ for the shade-intolerant species (Figure 1A, Supplement Figure S1A). The available evidence that we have therefore does not conclusively point to a systematic difference in C-balance between our shade-tolerant and intolerant species at the lowest irradiance, which is representative for deep canopy shade. Sterck et al. (2013) arrived at the same conclusion when comparing tropical shrubs of different shadetolerance, although they assumed a constant shoot and root $R_{\mathrm{m}}$. The number of species in our study is not large enough for broader generalizations, but when taking into account the literature data as cited above, the conclusion emerges that there is not much evidence for a systematic difference in C-balance between shade-tolerant and intolerant species at the low light levels found in deep shade under a dense canopy.

Mahmoud and Grime (1974) and Pons (1983) reduced irradiance to very low values and found no systematic difference between shade-tolerant and intolerant species in light compensation points. However, mortality was much higher for shade-intolerant species at and below the compensation point, and as far as surviving plants permitted, their RGR was estimated to be more negative. This suggests that shade-tolerant species can reduce $R$ further under C-starvation than shade-intolerant species.

Many shade-intolerant species, including the ones from this study, show a pronounced shade-avoidance response at the low red: far-red ratios in canopy shade light, which involves among others increased stem and petiole growth (Morgan and Smith, 1976; Kurepin et al., 2007; Pierik et al., 2011). This is not only likely to increase $R$, but may also go at the expense of LMF (Poorter et al., 2012b), thus reducing RGR (equation 1). Shadetolerant species, including Geum and to a lesser extent Impatiens, show a reduced shade-avoidance response in canopy shade light (Morgan and Smith, 1979; Corré, 1983b; Gommers et al., 2013). The reduced growth is likely to reduce $R$. This resembles the quiescent strategy found in submergence-tolerant species or genotypes (Bailey-Serres and Voesenek, 2008) that stop growth and reduce respiration under water where photosynthesis is negligible, as opposed to enhanced elongation growth under a negative C-balance of species that have an escape strategy such as Rumex palustris (Groeneveld and Voesenek, 2003). The latter shows similarities with the shade-avoidance response of shade-intolerant species, which furthermore negatively affects stem mechanics and strength (Anten et al., 2005), and can go on the expense of defense as is among others also documented for Chenopodium (Kurashige and Agrawal, 2005). Under natural conditions shade-intolerant species do normally not survive the lowest irradiance used in our experiment, which was equivalent to dense canopy shade. As we have little evidence for a more favorable C-balance of shade-tolerant species at the lowest irradiance under controlled conditions, tolerance to other biotic or a-biotic stresses (see discussion above) in combination with the low irradiance stress is likely to be more important for survival in canopy shade.

\section{CONCLUSIONS}

At high irradiance, the three shade-intolerant herbaceous species used in our experiment had a higher RGR compared to the two shade-tolerant species. This was associated with a higher $A_{\text {sat }}$ and consequently a higher ULR.

Daily whole-plant respiration as a fraction of gross photosynthesis $(R / A)$ was essentially constant at around 0.3 over a broad range of growth irradiances. Although shoot and root $R_{\mathrm{m}}$ decreased less with decreasing irradiance than $A_{\mathrm{m}}$, the decrease in $\mathrm{RMF}$ in combination with the much higher root $R_{\mathrm{m}}$ compared to shoot $R_{\mathrm{m}}$ explained the constancy of whole-plant $R / A$.

At the lowest irradiance, two of the three shade-intolerant species showed a tendency of a less efficient C-balance, but there were no systematic differences in RGR, ULR or R/A between the shade-tolerant and shade-intolerant species. No conclusive evidence was thus found for a less favorable C-balance between the two functional groups at the lowest irradiance.

Remarkable differences between the functional groups were a higher dry matter percentage, carbon concentration and constructions costs of leaf tissue for the shade-tolerant species. These traits could be associated with better defense and therefore increased leaf longevity in shade. Superior longevity and tolerance to other stresses at low irradiance are likely to be more decisive for 
survival at the low irradiance in canopy shade than a superior Cbalance.

\section{ACKNOWLEDGMENTS}

The experiments were carried out by Joost Rink and Carmen Gracia-Martín for their MSc thesis. Yvonne de Jong - van Berkel did additional measurements and carried out the chemical analyses.

\section{SUPPLEMENTARY MATERIAL}

The Supplementary Material for this article can be found online at: http://www.frontiersin.org/journal/10.3389/fpls.2014. 00012/abstract

\section{REFERENCES}

Amthor, J. S. (2000). The McCree-de Wit-Penning de Vries-Thornley respiration paradigms: 30 years later. Ann. Bot. 86, 1-20. doi: 10.1006/anbo. 2000.1175

Anten, N. P. R., Casado-Garcia, R., and Nagashima, H. (2005). Effects of mechanical stress and plant density on mechanical characteristics, growth, and lifetime reproduction of tobacco plants. Am. Nat. 166, 650-660. doi: 10.1086/497442

Atkin, O. K., Scheurwater, I., and Pons, T. L. (2007). Respiration as a percentage of daily photosynthesis in whole plants is homeostatic at moderate, but not high, growth temperatures. New Phytol. 174, 367-380. doi: 10.1111/j.14698137.2007.02011.x

Bailey-Serres, J., and Voesenek, L. A. C. J. (2008). Flooding stress: acclimations and genetic diversity. Ann. Rev. Plant Biol. 59, 313-339. doi: 10.1146/annurev.arplant.59.032607.092752

Blackman, G. E., and Wilson, G. L. (1951). Physiological and ecological studies in the analysis of plant environment VII. An analysis of the different effects of light intensity on the net assimilation rate, leaf area ratio, and relative growth rate of different species. Ann. Bot. 15, 373-408.

Chow, W. S., Qian, L., and Goodchild, D. J. (1988). Photosynthetic acclimation of Alocasia macrorrhiza (L.) G. Don to growth irradiance: structure, function and composition of chloroplasts. Aust. J. Plant Physiol. 15, 107-122. doi: 10.1071/PP9880107

Corré, W. J. (1983a). Growth and morphogenesis of sun and shade plants.1. The influence of light-intensity. Acta Bot. Neerl. 32, 49-62.

Corré, W. J. (1983b). Growth and morphogenesis of sun and shade plants.2. The influence of light quality. Acta Bot. Neerl. 32, 185-202.

Craine, J. M., and Reich, P. B. (2005). Leaf-level light compensation points in shade-tolerant woody seedlings. New Phytol. 166, 710-713. doi: 10.1111/j.14698137.2005.01420.x

Evans, C. G. (1972). The Quantitative Analysis of Plant Growth. Berkeley, CA: Blackwell Scientific Publications.

Evans, G. C., and Hughes, J. E. (1961). Plant growth and the earial environment I. effect of artificial shading on Impatiens parviflora. New Phytol. 60, 150-180. doi: 10.1111/j.1469-8137.1961.tb06249.x

Evans, J. R., and Poorter, H. (2001). Photosynthetic acclimation of plants to growth irradiance: the relative importance of specific leaf area and nitrogen partitioning in maximizing carbon gain. Plant Cell Environ. 24, 755-767. doi: 10.1046/j.1365-3040.2001.00724.x

Fredeen, A. L., Gamon, J. A., and Field, C. B. (1991). Responses of photosynthesis and carbohydrate-partitioning to limitations in nitrogen and water availability in field-grown sunflower. Plant Cell Environ. 14, 963-970. doi: 10.1111/j.13653040.1991.tb00966.x

Gifford, R. M. (1995). Whole plant respiration and photosynthesis of wheat under increased $\mathrm{CO}_{2}$ concentration and temperature: long-term vs short-term distinctions for modelling. Glob. Change Biol. 1, 385-396. doi: 10.1111/j.13652486.1995.tb00037.x

Gifford, R. M. (2003). Plant respiration in productivity models: conceptualisation, representation and issues for global terrestrial carbon-cycle research. Funct. Plant Biol. 30, 171-186. doi: 10.1071/FP02083

Givnish, T. J. (1988). Adaptation to sun and shade: a whole plant perspective. Aust. J. Plant Physiol. 15, 63-92. doi: 10.1071/PP9880063

Gommers, C. M. M., Visser, E. J. W., St. Onge, K. R., Voesenek, L. A. C. J., and Pierik, R. (2013). Shade tolerance: when growing tall is not an option. Trends Plant Sci. 18, 65-71. doi: 10.1016/j.tplants.2012.09.008
Groen, J. (1973). Photosynthesis of Calendula officinalis L. and Impatiens parviflora DC., as influenced by light intensity during growth and age of leaves and plants. Mededelingen Landbouwhogeschool. Wageningen Nederland 71, 1-128.

Groeneveld, H. W., and Voesenek, L. A. C. J. (2003). Submergence-induced petiole elongation in Rumex palustris is controlled by developmental stage and storage compounds. Plant Soil 253, 115-123. doi: 10.1023/A:1024511232626

Hanba, Y. T., Kogami, H., and Terashima, I. (2002). The effect of growth irradiance on leaf anatomy and photosynthesis in Acer species differing in light demand. Plant Cell Environ. 25, 1021-1030. doi: 10.1046/j.1365-3040.2002.00881.x

Hiroi, T., and Monsi, M. (1963). Physiological and ecological analysis of shade trolerance of plants 3. effects of shading on growth attributes of Helianthus annuus. Bot. Mag. Tokyo 76, 121-129.

Hoagland, D. R., and Snijder, W. C. (1933). Nutrition of strawberry plants under controlled conditions. Proc. Am. Soc. Hortic. Sci. 30, 288-296.

Houter, N. C., and Pons, T. L. (2012). Ontogenetic changes in leaf traits of tropical rainforest trees differing in juvenile light requirement. Oecologia 169, 33-45. doi: 10.1007/s00442-011-2175-x

Huxley, P. A. (1967). The effects of artificial shading on some growth characteristics of Arabica and Robusta coffee seedlings I. the effects of shading on dry weight, leaf area and derived growth data. J. Appl. Ecol. 4, 291-308. doi: $10.2307 / 2401337$

Jackson, L. W. R. (1967). Effect of shade on leaf structure of deciduous tree species. Ecology 48, 498-499. doi: 10.2307/1932686

Kitajima, K., Cordero, R. A., and Wright, S. J. (2013). Leaf life span spectrum of tropical woody seedlings: effects of light and ontogeny and consequences for survival. Ann. Bot. 112, 685-699. doi: 10.1093/aob/mct036

Kurashige, N. S., and Agrawal, A. A. (2005). Phenotypic plasticity to light competition and herbivory in Chenopodium album (Chenopodiaceae). Am. J. Bot. 92, 21-26. doi: 10.3732/ajb.92.1.21

Kurepin, L. V., Emery, R. J. N., Pharis, R. P., and Reid, D. M. (2007). Uncoupling light quality from light irradiance effects in Helianthus annuus shoots: putative roles for plant hormones in leaf and internode growth. J. Exp. Bot. 58, 2145-2157. doi: 10.1093/jxb/erm068

Lambers, H., Atkin, O. K., and Millenaar, F. F. (2002). "Respiratory patterns in roots in relation to their function," in Plant Roots: the Hidden Half, eds Y. Waisel, A. Eshel, and U. Kafkaki (New York, NY: Marcel Dekker Inc.), 521-552.

Loveys, B. R., Scheurwater, I., Pons, T. L., Fitter, A. H., and Atkin, O. K. (2002). Growth temperature influences the underlying components of relative growth rate: an investigation using inherently fast- and slow-growing plant species. Plant Cell Environ. 25, 975-988. doi: 10.1046/j.1365-3040.2002.00879.x

Lusk, C. H. (2002). Leaf area accumulation helps juvenile evergreen trees tolerate shade in a temperate rainforest. Oecologia 132, 188-196. doi: 10.1007/s00442002-0974-9

Lusk, C. H., Reich, P. B., Montgomery, R. A., Ackerly, D. D., and Cavender-Bares, J. (2008). Why are evergreen leaves so contrary about shade? Trends Ecol. Evol. 23, 299-303. doi: 10.1016/j.tree.2008.02.006

Lusk, C. H., and Warton, D. I. (2007). Global meta-analysis shows that relationships of leaf mass per area with species shade tolerance depend on leaf habit and ontogeny. New Phytol. 176, 764-774. doi: 10.1111/j.1469-8137.2007.02264.x

Mahmoud, A., and Grime, J. P. (1974). Comparison of negative relative growth rates in shaded seedlings. New Phytol. 73, 1215-1219. doi: 10.1111/j.14698137.1974.tb02150.x

McCree, K. J., and Troughton, J. H. (1966). Prediction of growth rate at different light levels from measured photosynthesis and respiration rates. Plant Physiol. 41, 559-566. doi: 10.1104/pp.41.4.559

Morgan, D. C., and Smith, H. (1976). Linear relationship between phytochrome photo-equilibrium and growth in plants under simulated natural radiation. Nature 262, 210-212. doi: 10.1038/262210a0

Morgan, D. C., and Smith, H. (1979). A systematic relationship between phytochrome controlled development and species habitat. Planta 145, 253-258. doi 10.1007/BF00454449

Murchie, E. H., and Horton, P. (1997). Acclimation of photosynthesis to irradiance and spectral quality in British plant species: chlorophyll content, photosynthetic capacity and habitat preference. Plant Cell Environ. 20, 438-448. doi: 10.1046/j.1365-3040.1997.d01-95.x

Niinemets, U. (1999). Energy requirement for foliage formation is not constant along canopy light gradients in temperate deciduous trees. New Phytol. 141, 459-470. doi: 10.1046/j.1469-8137.1999.00361.x

Noguchi, K., Nakajima, N., and Terashima, I. (2001). Acclimation of leaf respiratory properties in Alocasia odora following reciprocal transfers of plants 
between high- and low-light environments. Plant Cell Environ. 24, 831-839. doi: 10.1046/j.1365-3040.2001.00728.x

Noguchi, K., Sonoike, K., and Terashima, I. (1996). Acclimation of respiratory properties of leaves of Spinacea oleracea L., a sun species, and of Alocasia macrorrhiza (L.) G. Don., a shade species, to changes in growth irradiance. Plant Cell Physiol. 37, 377-384. doi: 10.1093/oxfordjournals.pcp.a028956

Noguchi, K., Taylor, N. L., Millar, A. H., Lambers, H., and Day, D. A. (2005). Response of mitochondria to light intensity in the leaves of sun and shade species. Plant Cell Environ. 28, 760-771. doi: 10.1111/j.1365-3040.2005.01322.x

Onoda, Y., Schieving, F., and Anten, N. P. R. (2008). Effects of light and nutrient availability on leaf mechanical properties of Plantago major: a conceptual approach. Ann. Bot. 101, 727-736. doi: 10.1093/aob/mcn013

Osborne, B. A., Clabby, G. T., Horsley, D., and Nolan, P. F. (1994). Is acclimation required for success in high light environments? A case study using Mycelis muralis (L.) Dumort (Asteraceae). New Phytol. 127, 363-375. doi: 10.1111/j.1469-8137.1994.tb04287.x

Petritan, A. M., von Lupke, B., and Petritan, I. C. (2010). A comparative analysis of foliar chemical composition and leaf construction costs of beech (Fagus sylvatica L.), sycamore maple (Acer pseudoplatanus L.) and ash (Fraxinus excelsior L.) saplings along a light gradient. Ann. For. Sci. 67, 610. doi: 10.1051/forest/2010023

Pierik, R., de Wit, M., and Voesenek, L. A. C. J. (2011). Growth-mediated stress escape: convergence of signal transduction pathways activated upon exposure to two different environmental stresses. New Phytol. 189, 122-134. doi: 10.1111/j.1469-8137.2010.03458.x

Pons, T. L. (1977a). An ecophysiological study in the field layer of ash coppice. II. Experiments with Geum urbanum and Cirsium palustre in different light intensities. Acta Bot. Neerl. 26, 29-42.

Pons, T. L. (1977b). An ecophysiological study in the field layer of ash coppice. III. Influence of diminishing light intensity during growth on Geum urbanum and Cirsium palustre. Acta Bot. Neerl. 26, 251-263.

Pons, T. L. (1983). An Ecophysiological Study in the Field Layer of Ash Coppice. Thesis, Utrecht University, Netherlands.

Pons, T. L., and Welschen, R. A. M. (2002). Overestimation of respiration rates in commercially available clamp-on leaf chambers. Complications with measurement of net photosynthesis. Plant Cell Environ. 25, 1367-1372. doi: 10.1046/j.1365-3040.2002.00911.x

Poorter, H. (1989). Plant growth analysis: towards a synthesis of the classical and functional approach. Physiol. Plant. 75, 237-244. doi: 10.1111/j.13993054.1989.tb06175.x

Poorter, H. (2002). Plant growth and carbon economy. Encyclopedia of Life Sci. 2002, 1-6. doi: 10.1038/npg.els.0003200

Poorter, H., Anten, N. P. R., and Marcelis, L. F. M. (2013). Physiological mechanisms in plant growth models: do we need a supra-cellular systems biology approach? Plant Cell Environ. 36, 1673-1690. doi: 10.1111/pce.12123

Poorter, H., Buhler, J., van Dusschoten, D., Climent, J., and Postma, J. A. (2012a). Pot size matters: a meta-analysis of the effects of rooting volume on plant growth. Funct. Plant Biol. 39, 839-850. doi: 10.1071/FP12049

Poorter, H., Niklas, K. J., Reich, P. B., Oleksyn, J., Poot, P., and Mommer, L. (2012b). Biomass allocation to leaves, stems and roots: meta-analyses of interspecific variation and environmental control. New Phytol. 193, 30-50. doi: 10.1111/j.1469-8137.2011.03952.x

Poorter, H., Niinemets, U., Poorter, L., Wright, I. J., and Villar, R. (2009). Causes and consequences of variation in leaf mass per area (LMA): a meta-analysis. New Phytol. 182, 565-588. doi: 10.1111/j.1469-8137.2009.02830.x

Poorter, H., Pepin, S., Rijkers, T., de Jong, Y., Evans, J. R., and Körner, C. (2006). Construction costs, chemical composition and payback time of high- and lowirradiance leaves. J. Exp. Bot. 57, 355-371. doi: 10.1093/jxb/erj002

Poorter, H., Remkes, C., and Lambers, H. (1990). Carbon and nitrogen economy of 24 wild species differing in relative growth rate. Plant Physiol. 94, 621-627. doi: 10.1104/pp.94.2.621

Poorter, H., van de Vijver, C. A. D. M., Boot, R. G. A., and Lambers, H. (1995). Growth and carbon economy of a fast growing and a slow growing grass species as dependent on nitrate supply. Plant Soil 171, 217-227. doi: $10.1007 / \mathrm{BF} 00010275$

Poorter, H., and van der Werf, A. (1998). "Is inherent variation in RGR determined by LAR at low irradiance and by NAR at high irradiance? A review of herbaceous species," in Inherent Variation in Plant Growth; Physiological Mechanisms and
Ecological Consequences, eds H. Lambers, H. Poorter, and M. M. I. van Vuuren (Leiden: Backhuys Publishers), 309-336.

Poorter, L. (1999). Growth responses of 15 rain forest tree species to a light gradient the relative importance of morphological and physiological traits. Funct. Ecol. 13, 396-410. doi: 10.1046/j.1365-2435.1999.00332.x

R Core Team (2013). R: A Language and Environment for Statistical Computing. Vienna: $\mathrm{R}$ Foundation for Statistical Computing. Available online at: http://www.R-project.org/

Renton, M., and Poorter, H. (2011). Using log-log scaling slope analysis for determining the contributions to variability in biological variables such as leaf mass per area: why it works, when it works and how it can be extended. New Phytol. 190, 5-8. doi: 10.1111/j.1469-8137.2010.03629.x

Sage, R. F., and Pearcy, R. W. (1987). The nitrogen use efficiency of C3 and C4 plants. II Leaf nitrogen effects on the gas exchange characteristics of Chenopodium album (L.) and Amaranthus retroflexus (L.). Plant Physiol. 84, 959-963. doi: 10.1104/pp.84.3.959

Shipley, B. (2006). Net assimilation rate, specific leaf area and leaf mass ratio: which is most closely correlated with relative growth rate? A meta-analysis. Funct. Ecol. 20, 565-574. doi: 10.1111/j.1365-2435.2006.01135.x

Sterck, F. J., Duursma, R. A., Pearcy, R. W., Valladares, F., Cieslak, M., and Weemstra, M. (2013). Plasticity influencing the light compensation point offsets the specialization for light niches across shrub species in a tropical forest understorey. J. Ecol. 101, 971-980. doi: 10.1111/1365-2745.12076

Terashima, I., Miyazawa, S. I., and Hanba, Y. T. (2001). Why are sun leaves thicker than shade leaves? Consideration based on analyses of $\mathrm{CO}_{2}$ diffusion in the leaf. J. Plant Res. 114, 93-105. doi: 10.1007/PL00013972

Valladares, F., Wright, S. J., Lasso, E., Kitajima, K., and Pearcy, R. W. (2000). Plastic phenotypic response to light of 16 congeneric shrubs from a Panamanian rainforest. Ecology 81, 1925-1936. doi: 10.1890/00129658(2000)081[1925:PPRTLO]2.0.CO;2

van der Werf, A., Welschen, R., and Lambers, H. (1992). "Respiratory losses increase with decreasing inherent growth rate of a species and with decreasing nitrate supply: a search for explanations for these observations," in Molecular Biochemical and Physiological Aspects of Plant Respiration, eds H. Lambers and L. H. W. van der Plas (The Hague: SPB Academic publishing), 421-432.

Veenendaal, E. M., Swaine, M. D., Lecha, R. T., Walsch, M. F., Abebrese, I. K., and Owusu-afriyie, K. (1996). Responses of west african forest tree seedlings to irradiance and soil fertility. Funct. Ecol. 10, 501-511. doi: 10.2307/2389943

Veneklaas, E. J., and Poorter, L. (1998). "Growth and carbon partitioning of tropical tree seedlings in contrasting light environments," in Inherent Variation in Plant Growth; Physiological Mechanisms and Ecological Consequences, eds H. Lambers, H. Poorter, and M. M. I. van Vuuren (Leiden: Backhuys Publishers), 337-361.

Walters, M. B., and Reich, P. B. (1999). Low light carbon balance and shade tolerance in the seedlings of woody plants do winter deciduous and broad leaved evergreen species differ. New Phytol. 143, 143-154. doi: 10.1046/j.14698137.1999.00425.x

Zotz, G., and Winter, K. (1993). Short-term photosynthesis measurements predict leaf carbon balance in tropical rain forest canopy plants. Planta 191, 409-412. doi: 10.1007/BF00195700

Conflict of Interest Statement: The authors declare that the research was conducted in the absence of any commercial or financial relationships that could be construed as a potential conflict of interest.

Received: 02 October 2013; accepted: 08 January 2013; published online: 04 February 2014.

Citation: Pons TL and Poorter H (2014) The effect of irradiance on the carbon balance and tissue characteristics of five herbaceous species differing in shade-tolerance. Front. Plant Sci. 5:12. doi: 10.3389/fpls.2014.00012

This article was submitted to Functional Plant Ecology, a section of the journal Frontiers in Plant Science.

Copyright (C) 2014 Pons and Poorter. This is an open-access article distributed under the terms of the Creative Commons Attribution License (CCBY). The use, distribution or reproduction in other forums is permitted, provided the original author(s) or licensor are credited and that the original publication in this journal is cited, in accordance with accepted academic practice. No use, distribution or reproduction is permitted which does not comply with these terms. 


\section{APPENDIX 1}

The relative growth rate (RGR), the increase in dry mass per unit plant mass and time, consists of three components, the unit leaf rate (ULR), the increase in dry mass per unit leaf area and time, the specific leaf area (SLA), the leaf area per leaf dry mass, and the leaf mass fraction (LMF), the leaf dry mass per plant mass (Evans, 1972).

$$
\text { RGR }=\text { ULR } . S L A . L M F
$$

The ULR as measured from the dry mass increment per unit leaf area can also be expressed as the daily net assimilation rate based on gas exchange (NAR $\mathrm{ge}_{\mathrm{g}}$ ).

$$
\mathrm{ULR} \approx \mathrm{NAR}_{\mathrm{ge}}=\left(A_{\text {growth }}-R_{\mathrm{a}}\right) /[C]
$$

(Poorter et al., 2013). $A_{\text {growth }}$ is daily whole-plant gross photosynthesis and $R_{\mathrm{a}}$ is daily whole-plant respiration both expressed per unit leaf area. The molar carbon concentration in plant dry matter $[C]$ converts net molar $\mathrm{CO}_{2}$ uptake to dry mass units. $\mathrm{NAR}_{\text {ge }}$ can also be calculated using the fraction of daily gross photosynthesis that is respired $(R / A)$, or the carbon use efficiency (CUE), the fraction of daily gross photosynthesis that is invested in growth $(\mathrm{CUE}=1-R / A)$.

$$
A_{\text {growth }}-R_{\mathrm{a}}=A_{\text {growth }} \cdot(1-R / A)=A_{\text {growth }} \cdot \text { CUE }
$$

